\title{
Antiviral effect of a derivative of isonicotinic acid enisamium iodide (FAV00A) against influenza virus
}

\author{
D. COCKING 1 , J. CINATL ${ }^{2}$, D. A. BOLTZ 3 , X. PENG 3 , W. JOHNSON ${ }^{3}$, M. MUZZIO $^{3}$, O. SYARKEVYCH ${ }^{4}$, \\ G. KOSTYUK ${ }^{4}$, A. GOY ${ }^{4}$, L. MUELLER ${ }^{*}$, V. MARGITICH ${ }^{4}$
}

\begin{abstract}
${ }^{1}$ Retroscreen Virology Ltd. London Biosciences Innovation Centre, 2 Royal College Street, Camden London, NW1 ONH, United Kingdom; ${ }^{2}$ Institut für Medizinische Virologie, Klinikum der Johann Wolfgang Goethe-Universität, Paul-Ehrlich-Str. 40, 60596 Frankfurt am Main, Germany; ${ }^{3}$ IIT Research Institute, 10 West 35th Street, Chicago, IL 60616, USA

${ }^{4}$ Farmak JSC, 63 Kyrylivska Street, Kyiv, 04080, Ukraine; ${ }^{5}$ Dr. Regenold GmbH, Zöllinplatz 4, D-79410, Badenweiler, Germany
\end{abstract}

Received October 2, 2017; revised February 19, 2018; accepted March 22, 2018

\begin{abstract}
Summary. - With only a single class of antiviral drugs existing for treatment of influenza (neuraminidase inhibitors), the search for novel effective compounds is urgently needed. We evaluated a low molecular mass compound, enisamium iodide (FAV00A), against influenza virus infections in primary differentiated normal human bronchial epithelial (NHBE) cells, and in ferrets. FAV00A $(500 \mu \mathrm{g} / \mathrm{ml})$ markedly inhibited influenza virus replication and reduced viral M-gene expression in NHBE cells. Treatment of ferrets with FAV00A (200 $\mathrm{mg} / \mathrm{kg}$ once daily for 7 days) initiated $24 \mathrm{~h}$ after inoculation with $10^{5} \mathrm{TCID}_{50}$ of influenza A/Wisconsin/67/2005 $(\mathrm{H} 3 \mathrm{~N} 2)$ virus resulted in a significant decrease in virus titers in the upper respiratory tract. Our data show that FAV00A exhibits an antiviral effect against influenza virus in NHBE cells and provides some benefits in a ferret model. Thus, further evaluation of FAV00A as a potential antiviral agent for treating influenza is warranted.
\end{abstract}

Keywords: antiviral agents; enisamium iodide; influenza virus; MDCK cells; NHBE cells; ferrets

Influenza is an acute respiratory disease in humans occurring globally with an annual attack rate estimated at 5\%-10\% in adults and $20 \%-30 \%$ in children. Influenza virus infection can result in hospitalization and death mainly among high-risk groups (the very young, elderly or chronically ill, and immunocompromised patients). Worldwide, these annual epidemics are estimated to cause about 3 to 5 million cases of severe disease, and about 250,000 to 500,000 deaths (WHO, 2017). Presently, only a few options are available that can reduce the impact of influenza immunoprophylaxis with an inactivated or live attenuated vaccine and treatment with influenza antiviral drugs. Seasonal influenza vaccines provide heterologous protection against both influenza $A$ and $B$ viruses. Their efficacy is dependent upon antigenic

*Corresponding author. E-mail: lutz.mueller@regenold.com; phone: $+49-7632-822-650$.

Abbreviations: $\mathrm{dpi}=$ days post infection; $\mathrm{FAV00A}=$ enisamium iodide; hpi $=$ hours post infection similarity to currently circulating viruses, and they may be less effective in high-risk groups (Breteler et al., 2013; Wijnans and Voordouw, 2016). When vaccine efficacy is reduced, or an immunologically naïve individual acquires influenza, antiviral therapies are an important second line of defense to manage acute influenza virus infection. Only one class of virus protein-specific antiviral drugs is available to combat influenza, the neuraminidase inhibitors (Fiore et al., 2011; De Jong et al., 2014). Approved neuraminidase inhibitors in the United States include oral oseltamivir, inhaled zanamivir, and injectable peramivir. Adamantanes (amantadine and rimantadine) are no longer recommended for antiviral treatment or chemoprophylaxis of currently circulating influenza infection because of widespread virus resistance (Bright et al., 2006, Boivin, 2013).

Influenza neuraminidase is a surface glycoprotein of the influenza virus that cleaves sialic acid residues from cellular glycoproteins and glycolipids which enables the virus to be released from the infected cell. The enzyme is responsible for the release of new viral particles from infected cells and 
(a)

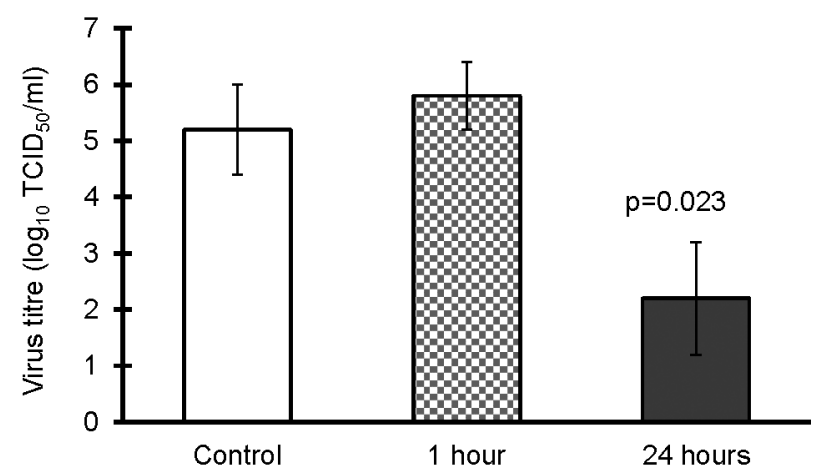

(b)

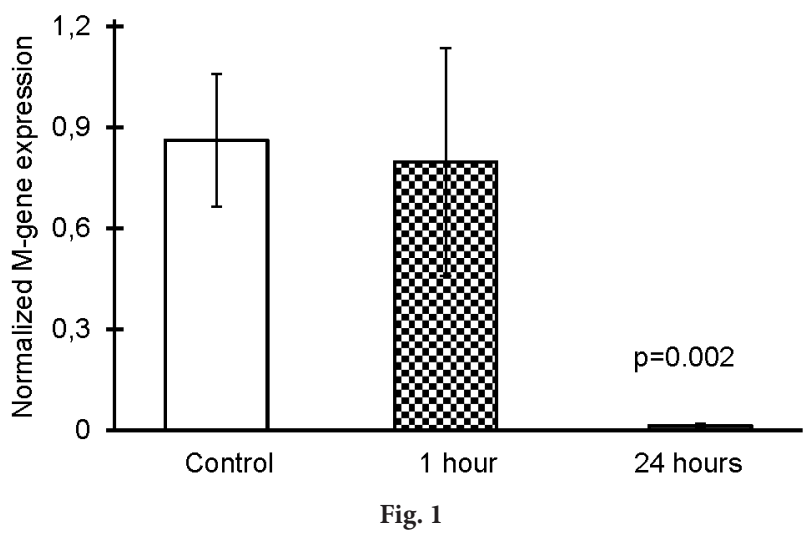

Effect of FAV00A on influenza A/Brisbane/59/2007 (H1N1) virus yield and $\mathrm{M}$-gene expression in differentiated NHBE cells

The cells were infected with influenza A/Brisbane/59/2007 (H1N1) virus a MOI 0.01 via the apical side for $1 \mathrm{~h}$ with subsequent removal and addition of FAV00A $(500 \mu \mathrm{mol} / \mathrm{l})$ via the basal side. (a) Reduction of virus titers (mean $\left.\pm \mathrm{SD}, \log _{10} \mathrm{TCID}_{50} / \mathrm{ml}\right)$ in the presence of FAV00A in the culture medium for 1 or $24 \mathrm{hpi}$. The samples from virus-infected untreated (control) and FAV00A-treated NHBE cells for either 1 or $24 \mathrm{~h}$ were collected at $24 \mathrm{hpi}$. (b) Down-regulation of M-gene expression (mean $\pm \mathrm{SD}$ ) in the presence of FAV00A in the culture medium for 1 or $24 \mathrm{hpi}$ as assessed by qRT-PCR. The expression of $\beta$-actin gene was used as a reference gene for normalization. $P$ values as compared to control samples (Student's $t$-test).

may assist in the spreading of virus through the mucus within the respiratory tract (Colman, 1994). The neuraminidase inhibitors represent an important advance in the management of influenza with respect to activity against influenza $A$ and $B$ viruses, with proven therapeutic value in reducing influenza lower respiratory complications (Laurent et al., 2003) and lower rates of antiviral drug resistance among currently circulating influenza viruses (Kiso et al., 2004, Okomo-Adhiambo et al., 2015). However, the use of these agents could be limited due to concerns including the degree of effectiveness, the need for an inhaler device nebulizer (i.e. for zanamivir), and the emergence of resistant influenza virus variants in some treated patients (Michiels et al., 2013).
Enisamium iodide (trade name: Amizon; lab code FAV00A), an antiviral agent which is currently used for the treatment of influenza in former Soviet Union countries and Mongolia. Up to date 845 million tablets/capsules of enisamium iodide were sold in these countries.

Here, we evaluated the in vitro antiviral activity of FAV00A against influenza virus infections in differentiated normal human bronchial epithelial (NHBE) cells, which serve as a target for naturally occurring influenza virus infections in humans. Recently it was demonstrated that the pattern of infection progression in NHBE cells correlated with autopsy studies of fatal cases from the 2009 pandemic influenza virus infection in humans (Davis et al., 2015). In addition, an in vivo study in a ferret model of acute influenza was conducted. Ferrets are a well-recognized animal model for investigation of influenza infections since this species shows similar symptoms of influenza infection as in humans (Belser et al., 2011). The results demonstrate FAV00A antiviral activity against influenza virus.

Differentiated NHBE cells were inoculated with influenza A/Brisbane/59/2007 (H1N1) virus by exposure of the apical side to influenza virus at a multiplicity of infection (MOI) of 0.01 . After $1 \mathrm{~h}$ incubation with virus at $37^{\circ} \mathrm{C}$ and $5 \% \mathrm{CO}_{2}$, the viral inoculum was removed from the cells. The apical side of the cells was washed once and cells exposed to FAV00A. At $24 \mathrm{~h}$ post infection (hpi), viruses released into the apical compartment of NHBE cells were harvested by the addition and collection of $500 \mu \mathrm{l}$ of growth medium which was allowed to equilibrate for $30 \mathrm{~min}$. The medium from the apical compartment was frozen and stored at $-65^{\circ} \mathrm{C}$ until use. Virus titers were determined in Madin-Darby canine kidney (MDCK) cells after incubation at $37 \pm 2{ }^{\circ} \mathrm{C}$ in $5 \%$ $\mathrm{CO}_{2}$ for $72 \mathrm{~h}$. The plates were scored for cytopathogenic effect (CPE) and the hemagglutination (HA) activity of the supernatant was assessed by HA assay with $0.5 \%$ packed guinea pig red blood cells (RBCs). Tissue culture infectious dose $50\left(\mathrm{TCID}_{50}\right)$ was determined as described earlier (Reed and Munch, 1938). The 50\% cytotoxic concentration $\left(\mathrm{CC}_{50}\right)$ of FAV00A was assessed in NHBE cells by MTT [3-(4,5dimethylthiazol-2-yl)-2,5-diphenyltetrazolium bromide] assay (Sigma-Aldrich, USA) (Mosmann, 1983).

Total RNA was isolated from cells using Trizol (Rio et al., 2010) following the manufacturer's instruction. Total RNA was dissolved in RNase-free water and quantitated using a Biomate 5 spectrophotometer (Thermo Electron Corp., USA) at 260/280 nm. Reverse transcriptase (RT) was done in a final volume of $20 \mu \mathrm{l}$ with $2 \mu \mathrm{g}$ total RNA and $100 \mathrm{U}$ of MuLV RT (Invitrogen, USA) for $50 \mathrm{~min}$ at $42^{\circ} \mathrm{C}$. Duplicate RT samples (cDNA) for each RNA sample were generated, then the two cDNA samples were pooled and diluted with RNase-free water by 2 -fold. The cDNA (total $80 \mu \mathrm{l}$ ) samples were stored at $-80^{\circ} \mathrm{C}$ until further qPCR analysis. The gene specific primer pairs (and product size) for the genes analyzed were: $\mathrm{M}$-gene 
forward 5'-TCAGGCCCCCTCAAAGCCGAGAT-3' and reverse 5'-CGTCTACGCTGCAGTCCTC-3' (185 bp), $\beta$-actin forward 5'-CTCTTCCAGCCTTCCTTCCT-3' and reverse 5'-AGCACTGTGTTGGCGTACAG-3' (116 bp). $\beta$-actin expression was used as a reference gene for normalization.

Male ferrets (Retroscreen Virology Ltd., London, UK) aged 3-5 months were screened by HA inhibition (HI) assay to ensure seronegativity to currently circulating human influenza $\mathrm{A}(\mathrm{H} 1 \mathrm{~N} 1), \mathrm{A}(\mathrm{H} 3 \mathrm{~N} 2)$ and $\mathrm{B}$ viruses. Animals were housed in groups of 8 in floor pens in a thermostatically monitored room and exposed to $16 \mathrm{~h}$ fluorescent lighting and $8 \mathrm{~h}$ dark per day. Animals were acclimatized for a minimum of 7 days prior to use. Ferrets were anesthetized with isoflurane, and each was inoculated intra-nasally with $5.0 \log _{10}$ $\mathrm{TCID}_{50} / \mathrm{ml}$ influenza A/Wisconsin/67/2005 (H3N2) virus in $0.5 \mathrm{ml}$ sterile phosphate buffered saline (PBS). FAV00A in the dose $200 \mathrm{mg} / \mathrm{kg}$ was administered by oral gavage once daily from -3 to -1 days before challenge as prophylactic regimen. The animals in the treatment regimen were given FAV00A (200 mg/kg) orally or oseltamivir $(10 \mathrm{mg} / \mathrm{kg})$ once daily at 1 to 7 days post infection (dpi). Control (uninfected, untreated) animals received sterile PBS delivered orally. Clinical signs of disease, body weight and temperature were recorded daily. Body temperature was measured twice daily by subcutaneous implantable temperature transponders (BMDS IPTT-300 injectable transponders) using the BMDS DAS-5002/DAS-6001system. Animals were weighed using SG1600 Mettler Toledo scales. At 1 to 7 dpi, ferrets were anesthetized by intramuscular injection of ketamine $(25 \mathrm{mg} / \mathrm{kg})$, and $0.5 \mathrm{ml}$ sterile PBS was instilled into each nostril for collection of nasal washes. Virus in the nasal washes of ferrets
( $\mathrm{n}=8$ /group) was titrated in MDCK cells and expressed as $\mathrm{TCID}_{50} / \mathrm{ml}$.

Virus titers in NHBE cells as well as M-gene expressionrelated normally distributed parametric data were analyzed by Student's $t$-test or one-way analysis of variance (ANOVA). The virus titers in nasal washes of ferrets were compared by one-way ANOVA, followed by the Bonferroni posttest. A probability $(P)$ value of $<0.05$ was prospectively chosen to indicate that the result was not attributable to chance.

After inoculation of NHBE cells with influenza A/ Brisbane/59/2007 (H1N1) virus, FAV00A $(500 \mu \mathrm{g} / \mathrm{ml})$ was added into the culture medium for 1 or $24 \mathrm{~h}$. At $24 \mathrm{hpi}$, apical washes were collected from the NHBE cell culture to determine the viral titers and level of M-gene expression.

Incubation of infected cells with FAV00A for $1 \mathrm{~h}$ produced no antiviral effect when compared with virus control. In contrast, a $3.6 \log _{10} \mathrm{TCID}_{50} / \mathrm{ml}$ reduction of viral titers was observed after $24 \mathrm{~h}$ incubation in the presence of FAV00A in cell culture medium (Fig. 1a). Viral M-gene expression of infected NHBE cells treated with FAV00A was conducted in parallel with the assessment of viral titers. A $1 \mathrm{~h}$ treatment of virus-infected NHBE cells with FAV00A was insufficient to reduce $\mathrm{M}$-gene expression (Fig. 1b). However, incubation of infected cells with FAV00A for $24 \mathrm{~h}$ demonstrated a marked inhibition of the viral $M$ gene expression, suggesting that FAV00A possesses an inhibitory effect on viral replication. It was found that $\mathrm{CC}_{50}$ of FAV00A in NHBE cells is as high as $32 \mathrm{mmol} / \mathrm{l}$ or $11.3 \mathrm{mg} / \mathrm{ml}$ (selectivity index 22.7), suggesting that the antiviral effect is not linked to cytotoxicity.

An oral dose of $200 \mathrm{mg} / \mathrm{kg}$ of FAV00A once daily was selected as a treatment regimen for the efficacy study in ferrets.

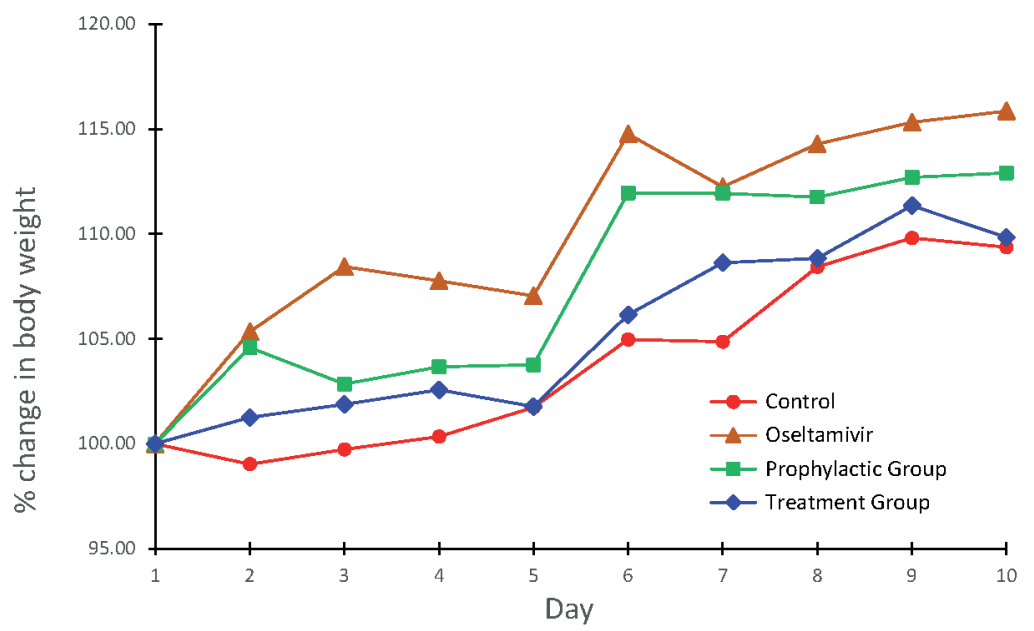

Fig. 2

Effect of FAV00A prophylactic and treatment ( $24 \mathrm{hpi}$ ) regimens on body weight of ferrets inoculated with A/Wisconsin/67/2005 (H3N2) influenza virus

The loss or gain of weight was calculated for each ferret as a percentage of its weight before virus inoculation. Values are means \pm SD, $\%$ ( $n=8$ ferrets/group). 
(a)

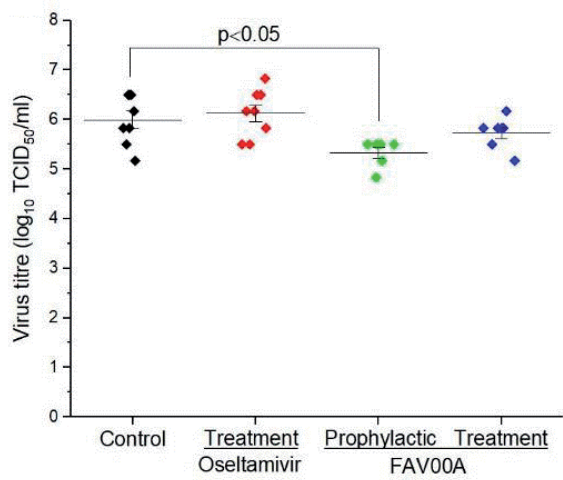

(d)

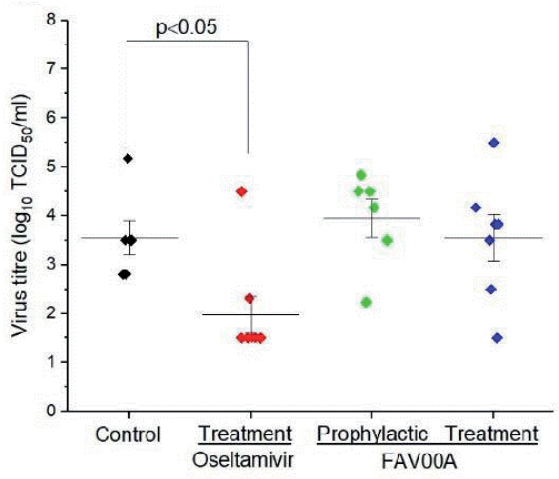

(g)

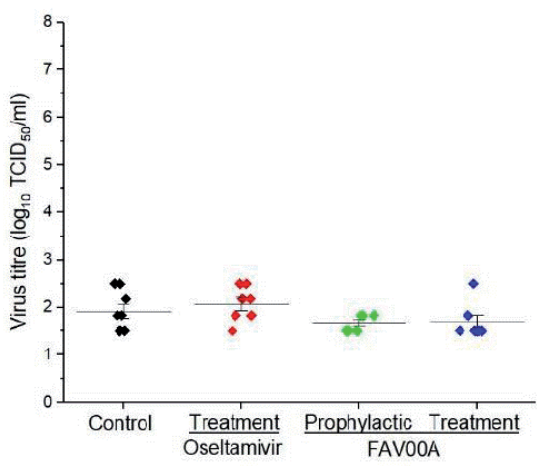

(b)

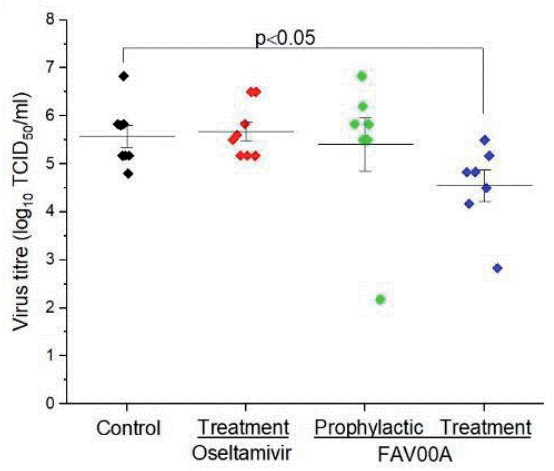

(e)

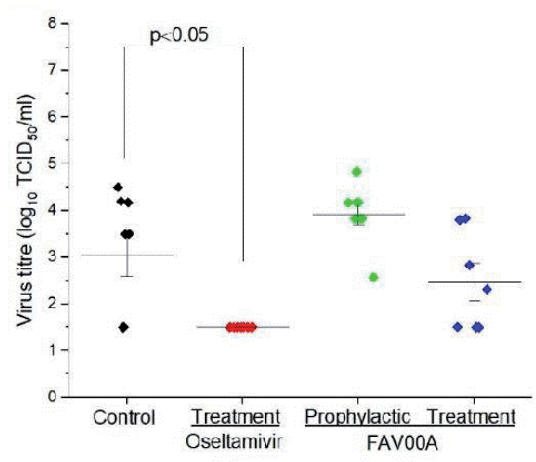

(h)

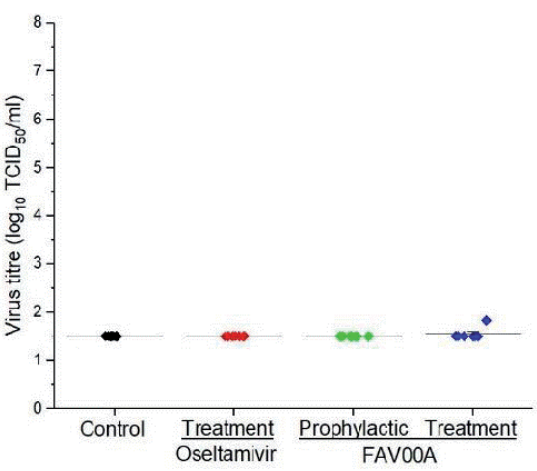

Fig. 3 (c)

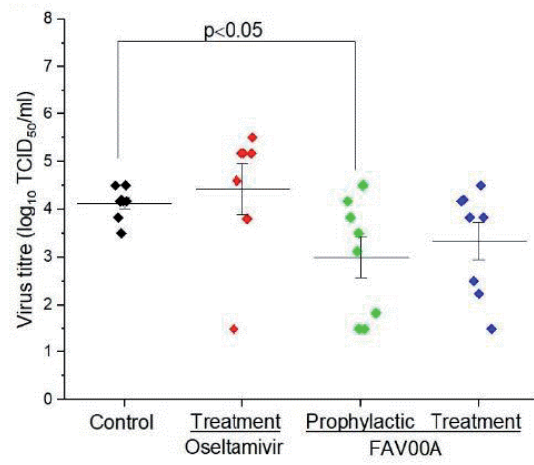

(f)

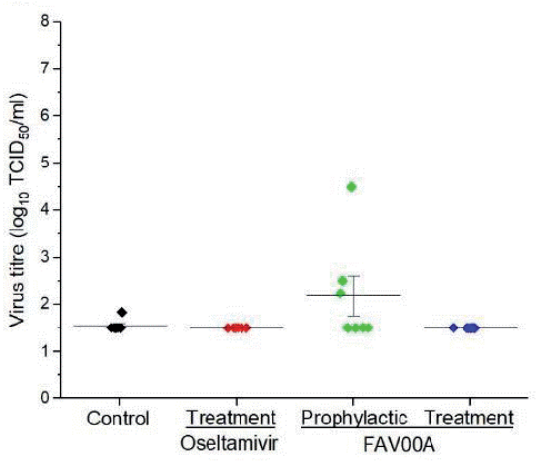

(i)

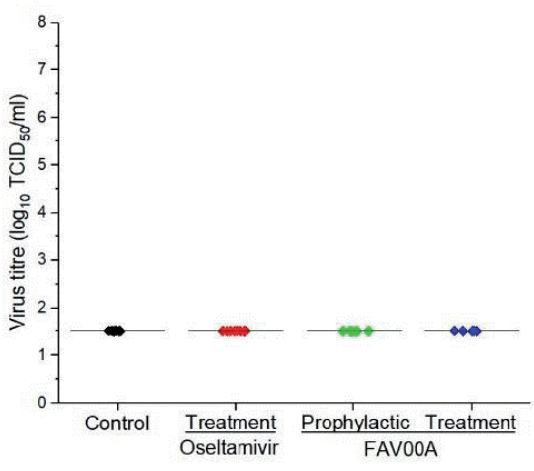

Effect of FAV00A prophylactic and treatment regimens on virus titers in nasal washes of ferrets infected with influenza A/Wisconsin/67/2005 (H3N2) virus at $1-9$ dpi

Virus titers (mean $\left.\pm \mathrm{SD}, \log _{10} \mathrm{TCID}_{50} \mathrm{ml}\right),\left(\mathrm{n}=8\right.$ ferrets/group). (a) $1^{\text {st }} \mathrm{dpi}$, (b) $2^{\text {nd }} \mathrm{dpi}$, (c) $3^{\text {rd }} \mathrm{dpi}$, (d) $4^{\text {th }} \mathrm{dpi}$, (e) $5^{\text {th }} \mathrm{dpi}$, (f) $6^{\text {th }} \mathrm{dpi}$, (g) $7^{\text {th }} \mathrm{dpi}$, (h) $8^{\text {th }} \mathrm{dpi}$, (i) $9^{\text {th }}$ dpi. $P$ values as compared to control ferrets (one-way ANOVA).

Eight animals of the treated group were drug-treated on days 1 to 7 after influenza A/Wisconsin/67/2005 (H3N2) virus inoculation. Control (infected, untreated) ferrets, as well as FAV00A and oseltamivir-treated animals, showed no signs of inactivity/lethargy (data not presented).

Infection of ferrets with influenza A/Wisconsin/67/2005 (H3N2) virus caused a slight decrease in mean body weight of the control animals, which returned to baseline values at $4 \mathrm{dpi}$. No significant effects of FAV00A or oseltamivir on body weight were seen (Fig. 2). Statistically significant decrease of viral titers determined in nasal washes of ferrets which prophylactically received FAV00A was observed on $1^{\text {st }}$ and $3^{\text {rd }}$ dpi. The treatment of experimental animals with FAV00A initiated $24 \mathrm{~h}$ after the virus inoculation lead to marked reduction of viral titers in their 
nasal washes when compared to the control group $(P<0.05)$. Oseltamivir treatment of virus-infected ferrets demonstrated a similar effect on $4^{\text {th }}$ and $5^{\text {th }}$ dpi. After $6^{\text {th }}$ dpi viral titers in ferret nasal washes in all experimental and control groups did not exceed their limits of detection (Fig. 3).

Thus, FAV00A exerted a strong antiviral effect against influenza virus replication in NHBE cells. This effect was confirmed by the nearly complete inhibition of viral M-gene expression, indicating that FAV00A suppresses viral RNA synthesis in differentiated NHBE cells. The mode of action of FAV00A still needs to be further investigated.

The efficacy of FAV00A was evaluated in a ferret model of influenza A virus infection. Ferrets infected with influenza A/Wisconsin/67/2005 (H3N2) virus produced minor clinical sings of infection. Body temperature elevation was not significant following the inoculation with influenza A(H3N2) virus. Similarly, body weight was not significantly reduced. However, virus titers in the nasal washes of the FAV00A-treated ferrets were significantly decreased comparing to those in control animals, which provided evidence of antiviral benefits. Further studies are needed to validate the antiviral activity in respect of other strains of influenza virus and explore the mechanism of action of FAV00A.

Acknowledgments. The authors would like to thank Dr. Elena Govorkova (St Jude Children Research Hospital, Memphis, TN, USA) and Dr. Donald Smee (Institute for Antiviral Research, Utah State University, Logan, UT, USA) for fruitful discussion and valuable recommendations, Dr. Rajendra Mehta (IIT Research Institute, Chicago, IL, USA) for valuable ideas regarding study design and discsussion of results; as well as Andriy Maslyanko (Medical Writer, Farmak, Kyiv, Ukraine) and Ivan Vovk (Specialist of Researches) for providing assistance with the preparation of this manuscript.

\section{References}

Belser JA, Katz JM, Terrence M. Tumpey TM. (2011): The ferret as a model organism to study influenza A virus infection. Dis. Models \& Mech. 4, 575-579. https://doi.org/10.1242/ dmm.007823

Boivin G (2013): Detection and management of antiviral resistance for influenza viruses. Influenza Other Respir. Viruses 7(Suppl. 3), 18-23. https://doi.org/10.1111/irv.12176

Breteler JK, Tam JS, Jit M, Ket JC, De Boer MR (2013): Efficacy and effectiveness of seasonal and pandemic A (H1N1) 2009 influenza vaccines in low and middle income countries: a systematic review and meta-analysis. Vaccine $31,5168-$ 5177. https://doi.org/10.1016/j.vaccine.2013.08.056

Bright RA, Shay DK, Shu B, Cox NJ, Klimov AI (2006): Adamantane resistance among influenza A viruses isolated early during the 2005-2006 influenza season in the United States. JAMA 295, 891-894. https://doi.org/10.1001/ jama.295.8.joc60020
Colman PM (1994): Influenza virus neuraminidase: structure, antibodies, and inhibitors. Protein Sci. 3,1687-1696. https://doi.org/10.1002/pro.5560031007

Davis AS, Chertow DS, Moyer JE, Suzich J, Sandouk A, Dorward DW, Logun C, Shelhamer JH, Taubenberger JK (2015): Validation of normal human bronchial epithelial cells as a model for influenza $\mathrm{A}$ infections in human distal trachea. J. Histochem. Cytochem. 63, 312-328. https:// doi.org/10.1369/0022155415570968

De Jong MD, Ison MG, Monto AS, Metev H, Clark C, O'Neil B, Elder J, McCullough A, Collins P, Sheridan WP (2014): Evaluation of intravenous peramivir for treatment of influenza in hospitalized patients. Clin. Infect. Dis. 59, 172-185. https://doi.org/10.1093/cid/ciu632

Fiore AE, Fry A, Shay D, Gubareva L, Bresee JS, Uyeki TM (2011): Antiviral agents for the treatment and chemoprophylaxis of influenza-recommendations of the Advisory Committee on Immunization Practices (ACIP). MMWR Recomm. Rep. 60, 1-24.

Kiso M, Mitamura K, Sakai-Tagawa Y, Shiraishi K, Kawakami C, Kimura K, Hayden FG, Sugaya N, Kawaoka Y (2004): Resistant influenza A viruses in children treated with oseltamivir: descriptive study. Lancet 364, 759-765. https://doi.org/10.1016/S0140-6736(04)16934-1

Laurent K, Wat C, Mills T, Mahoney P, Ward P, Hayden F (2003): Impact of oseltamivir treatment on influenza-related lower respiratory tract complications and hospitalizations. Arch. Intern. Med. 163, 1667-1672. https://doi. org/10.1001/archinte.163.14.1667

Michiels B, Van Puyenbroeck K, Verhoeven V, Vermeire E, Coenen $S$ (2013): The value of neuraminidase inhibitors for the prevention and treatment of seasonal influenza: a systematic review of systematic reviews. PLoS ONE 8, e60348. https://doi.org/10.1371/journal.pone.0060348

Mosmann T (1983): Rapid colorimetric assay for cellular growth and survival: application to proliferation and cytotoxicity assays. J. lmmunol. Methods 65, 55-63. https://doi. org/10.1016/0022-1759(83)90303-4

Okomo-Adhiambo M, Fry AM, Su S, Nguyen HT, Elal AA, Negron E, Hand J, Garten RJ, Barnes J, Xiyan X, Villanueva JM, Gubareva LV (2015): Oseltamivir-resistant influenza A (H1N1)pdm09 viruses, United States, 2013-14. Emerg. Infect. Dis. 2, 136-141. https://doi.org/10.3201/ eid2101.141006

Reed LJ, Muench H (1938): A simple method of estimating fifty percent endpoints. Am. J. Hyg. 27, 493-497.

Rio DC, Ares M Jr, Hannon GJ, Nilsen TW (2010): Purification of RNA using TRIzol (TRI reagent). Cold Spring Harb. Protoc. 6, pdb.prot5439. https://doi.org/10.1101/pdb. prot5439

Wijnans L, Voordouw B (2016): A review of the changes to the licensing of influenza vaccines in Europe. Influenza Other Respir. Viruses 10, 2-8. https://doi.org/10.1111/ irv. 12351

World Health Organization (WHO). Influenza (Seasonal). http:// www.who.int/mediacentre/factsheets/fs211/en/. Accessed 21 February 2017. 